CUADERNOS DE ESTUDIOS GALLEGOS, LVIII N. ${ }^{\circ} 124$, enero-diciembre (2011), pp. 79-98 ISSN 0210-847 X

\title{
EL OFICIO DE LA TRASLACIÓN DEL APÓSTOL SANTIAGO EN LA BAJA EDAD MEDIA: A PROPÓSITO DE UN FRAGMENTO DE ANTIFONARIO HALLADO EN LA CATEDRAL DE SEGOVIA
}

SANTIAGO RUIZ TORRES

Universidad Complutense (UCM) 


\title{
EL OFICIO DE LA TRASLACIÓN DEL APÓSTOL SANTIAGO EN LA BAJA EDAD MEDIA: A PROPÓSITO DE UN FRAGMENTO DE ANTIFONARIO HALLADO EN LA CATEDRAL DE SEGOVIA
}

\begin{abstract}
RESUMEN
Las investigaciones realizadas en torno a la música compuesta para el culto del apóstol Santiago suelen ceñirse por lo general al Codex Calixtinus. Aunque constituye un documento verdaderamente excepcional, muestra poca relación con las diversas expresiones líricas jacobeas difundidas por la Península Ibérica a lo largo de la Baja Edad Media. El hallazgo en la Catedral de Segovia de un fragmento de antifonario fechado a finales del siglo XIII con parte del Oficio de la Traslación, posibilitará conocer por vez primera parte del corpus musical compilado en el Medioevo para esta celebración. Por medio de un análisis se ilustrará acerca de sus estructuras modales, melódicas y textuales, y su relación respecto a otros repertorios como el gregoriano o la música del propio Calixtino. De igual modo, se examinarán los motivos que impulsaron la creación de esta celebración y la difusión que alcanzó por la Península. A su vez, se tratará de datar el origen del oficio en la forma en que aparece en el fragmento segoviano y se detallarán las causas que provocaron su remodelación tras el Concilio de Trento. Por último, se compararán las series responsoriales y antifonales de este oficio reflejadas en distintas fuentes litúrgicas peninsulares con objeto de conocer el grado de uniformidad en la transmisión de sus textos.
\end{abstract}

Palabras Clave: Santiago apóstol, Oficio de la Traslación, liturgia, monodia, Codex Calixtinus, responsorio, antífona.

\section{THE OFFICE OF THE TRANSLATION OF THE APOSTLE JAMES IN THE LATE MIDDLE AGES: ON THE SUBJECT OF A FRAGMENT OF ANTIPHONARY FOUND IN THE CATHEDRAL OF SEGOVIA}

\begin{abstract}
The research made with regard to the music composed for the cult of the Apostle James is generally based on the Codex Calixtinus. Although the Codex is an outstanding source, it has little connection with the varied and widespread Jacobean lyrical expressions in the Iberian Peninsula throughout in the late Middle Ages. The discovery of this thirteenth-century antiphonary fragment from the Office of the Translation of St James in the cathedral of Segovia, will provide a glimpse, for the first time, of a part of the musical corpus compiled for the feast of St. James in the Middle Ages. The analysis presented here explores the applicability of modal, melodic and textual structures and their relationships with other repertoires, such as Gregorian chant or the works from the Calixtinus codex. At the same time, this study will examine the motives that promoted the creation of this celebration and its diffusion in the Iberian world. Moreover, it is hoped that this multi-faceted approach will attempt to date the origin of this religious service in the form that appears in the Segovia fragment, and also will detail the reasons of its reform after the Council of Trent. In conclusion, it will be compared to both the antiphonal and the responsorial series of this office, from different Spanish liturgical sources, with the aim of understanding the degree of uniformity in the transmission of its texts.
\end{abstract}

KEY wORDS: Apostle James, Translation Office, liturgy, plainchant, Codex Calixtinus, responsory, antiphon. 
Recibido/Received: 02/09/2010

Aceptado/Accepted: 27/07/2011

$\mathrm{E}$

$\mathrm{N}$ un reciente trabajo sobre los fragmentos litúrgico-musicales conservados en el Archivo de la Catedral de Segovia, pude hallar un pergamino de unos 230x327 mm que contenía parte del Oficio de maitines de la Traslación del apóstol Santiago ${ }^{2}$. Dicho pergamino formaba parte, junto a otros 15 fragmentos, de un antifonario de finales del siglo XIII vinculado al culto local, el cual posiblemente pudo estar en uso hasta mediados del siglo XV.

En concreto, el fragmento contiene seis cantos: tres responsorios, dos antífonas y un versículo; salvo una antífona, el resto de piezas se hallan incompletas. Mencionar, asimismo, que las antífonas presentan la peculiaridad de hallarse en verso $^{3}$. Para mejor compresión del documento, transcribimos a continuación los textos de forma íntegra, a excepción del conocido versículo del Común de apóstoles Nimis honorati sunt. Tomaremos para las partes no incluidas en el fragmento la redacción ofrecida por el Breviario de Segovia B-272, datado a mediados del siglo $\mathrm{XV}^{4}$, por ser el testimonio local que más se le aproxima en el tiempo. En negrita figuran las partes incluidas en el fragmento:

\footnotetext{
2 Segovia, AC: Museo 24; véase ficha catalográfica № 23.1 en RuIz TorREs, Santiago, La monodia medieval en Segovia: Reflexiones en torno a la catalogación de unos fragmentos de códices litúrgicos, DEA, Universidad Complutense de Madrid 2008, 71. Catalogado como No 25.1 en Ídem, "El rito romano en la Segovia medieval: catalogación y análisis de unos fragmentos litúrgicos (siglos XII-XVI)", Hispania Sacra, LXII/126 (2010), 407-55.

${ }^{3}$ Se puede consultar la relación de textos en verso para este oficio en DREves, Guido Maria (ed.), Analecta Hymnica Medii Aevi XVII. Hymnodia Hiberica. Liturgische Reimofficien, Carmina Compostellana, Leipzig 1894, núm. 42, 119-20.

4 JANINI, José, "Códices litúrgicos de la catedral de Segovia", Estudios Segovianos, 15 (1963), núm. 10, 303-04; Ídem, Manuscritos litúrgicos de las Bibliotecas de España 1, Burgos 1977, núm. 308, 259-60. Conviene precisar que la actual signatura topográfica del Archivo de la Catedral de Segovia data de 1975, fecha en la que se efectuó el traslado del fondo a su presente ubicación, dato no proporcionado por Janini.
} 
RESPONSORIOS:

- O magnum dei munus et admirabile donativum ut in finibus Gallecie sydus aureum luceat in Hyspania novo lumine. Cujus splendor illuminat dei sanctos celos et mundum / Gaude ergo Hyspania tuo exuta errore supersticionis tripudia tanto illustrata jubare lucis

- Sancta et preadmiranda festivitas magnus glorie letabunda tropheis. Quia datus est hodie hyspaniis inclitus a deo patronus / Urbibus tu feliciorum cunctis Compostella elegit te quia sanctissimus iste ideoque gaude

- Felix valde es o terra Hispanie rerum copia plurimarum sed feliciorem beati Jacobi dotata presentia / Olim tu quidem pro columnis Hercolis fama vane opinionis gloriosa eras et que in tua dulce temperie assimilata es sacro padiso

ANTÍFONAS:

- Dracho peringens rumpitur tauri fortes domantur fera matrona vincitur in loca consecrantur

- Visis tantis miraculis matrona baptizatur et reprobatis ydolis sepultura paratur

El primer elemento que llama la atención es que ninguno de estos textos figura en el Codex Calixtinus. De hecho, tras revisar diversas fuentes litúrgicas peninsulares entre los siglos XIV y XVI, las redacciones encontradas para este oficio son las que verificamos en Segovia con ligeras variantes. Ello constituye una prueba decisiva para ratificar la limitada difusión del repertorio del Calixtino.

\section{ESTRUCTURAS MODALES, MELÓDICAS Y TEXTUALES}

El análisis del repertorio hallado en el manuscrito puede aportar algunos datos interesantes en relación a la composición de monodia litúrgica durante la Baja Edad Media. Si nos fijamos en las transcripciones [véanse ejemplos 1-5], observamos que todas las piezas, a excepción de la antífona Dracho peringens, optan por un modo plagal: modo II para los responsorios y modo VI para la antífona Visis tantis. La antífona Dracho peringens resulta algo ambigua en este punto. Según su nota final se le debe asignar un modo I, pero su desarrollo melódico y diferencia salmódica son más bien propios del modo VI. Su lenguaje, como se puede ver, no resulta muy diferente al que evidenciamos en Visis tantis. Sin embargo, debemos tener presente que el manuscrito sólo recoge la mitad de la pieza $\mathrm{y}$, por tanto, cualquier conclusión que se saque al respecto ha de ser vista con cau- 
tela. También el responsorio O magnum dei munus evidencia síntomas de cierta ambigüedad modal. La oscilación en torno a la cuerda FA del final de la primera sección parece indicar que nos hallamos ante un modo II, si bien el versículo refleja un ámbito ajeno a dicho modo (FA-DO). A primera vista se podría establecer una correspondencia del mencionado versículo con el lenguaje musical de las antífonas, pero su recitación sobre la cuerda SOL, es decir un "protus" a la cuarta, demuestra su adscripción al ámbito de RE. Aunque no podemos excluir que el responsorio se halle en modo I, estimamos como más probable el II a pesar de la elevación de la tesitura en el versículo, rasgo este último bastante normal si se tiene en cuenta que era la sección destinada al solista. La ausencia de una cuerda de dominante LA en la pieza y la mayor incidencia en FA, sobre todo en el cuerpo del responsorio, corroboran esta asignación de la pieza al "protus" plagal.

Si nos fijamos en el ámbito melódico, vemos cómo todos los cantos se ajustan a lo que es habitual en relación a su naturaleza modal. Ninguno de ellos sobrepasa la octava, ni se acoge a un modo mixto, rasgos que atestiguan una filiación con el corpus más primitivo del canto gregoriano. Otros atributos que refuerzan esta vinculación son el comentado "protus" a la cuarta de $O$ magnum dei munus, el cuidado de las conducciones cadenciales, la vecindad del SI y SIb en la antífona Visis tantis o la escasa proliferación del MI en dicha antífona, lo cual podría generar una falsa sensación de sensible ${ }^{5}$. Se puede afirmar, pues, que el compilador o compiladores de este oficio parecen conocer bastante bien el lenguaje gregoriano. Si extrapolamos estos datos con el repertorio monódico del Calixtino verificamos la concepción más moderna de éste. Francisco Javier Lara subraya en su estudio sobre las estructuras modales del Codex el notable desarrollo melódico que poseen sus cantos monódicos, el cual supera con frecuencia el ámbito del "octoechos" 6 . Al igual que sucede en oficios tardíos como el de la Trinidad o el del Corpus Christi, sus piezas además se colocan siguiendo el orden de los modos, algo que no observamos en el repertorio del fragmento segoviano, compuesto presuntamente más tarde ${ }^{7}$.

Con todo, advertimos en las piezas de nuestro manuscrito elementos de mayor modernidad como son la ausencia de melodías-tipo, centones o la inexistencia de saltos mayores al intervalo de $3^{\mathrm{a}}$, rasgo este último compartido por el Codex ${ }^{8}$.

\footnotetext{
5 Todos estos rasgos son explicados de forma más exhaustiva en JEANNETEAU, Jean, Los modos gregorianos. Historia, Análisis, Estética, Abadía de Silos 1985.

${ }^{6}$ Lara Lara, Francisco Javier, "Estructuras modales en el Códice Calixtino", El Códice Calixtino y la música de su tiempo. Actas del simposio organizado por la Fundación Pedro Barrié de la Maza en A Coruña y Santiago de Compostela, 20 - 23 de septiembre de 1999, A Coruña 2001, 275.

7 Acerca de la composición en orden de modos consúltese Huglo, Michel, Les tonaires: inventaire, analyse, comparaison, Paris 1971, 122-28.

${ }^{8}$ LARA LARA, "Estructuras modales", 291. Las melodías gregorianas se desenvuelven también preferentemente por grados conjuntos, si bien se producen con cierta frecuencia saltos de $4^{\mathrm{a}}, 5^{\mathrm{a}}$ y muy rara vez de $6^{\mathrm{a}}$, hecho que le confiere una notable expresividad.
} 
Asimismo, el hecho de que los textos de las antífonas estén en verso parece repercutir en el plano melódico, al menos en la antífona Visis tantis. En efecto, su elaboración melódica responde a una forma estrófica propia de los himnos. De este modo, tendríamos una primera sección que abarcaría hasta "baptizatur", seguida de la conjunción "et" que funcionaría como puente, y a partir de "reprobatis" se volvería a retomar, con ligeras variantes, la melodía del inicio. Esta semejanza entre ambas partes queda reforzada por medio de la fórmula melódica de "matrona/sepultura" basada en la vecindad entre SI y SIb, un diseño, sin duda, muy perceptible en la pieza. Podríamos pues, en base a lo que hemos comentado, calificar Visis tantis como una forma bipartita bastante equilibrada en sus dos secciones.

Igualmente, se pone de relieve en estas composiciones la estrecha unión textomelodía. Las notas de especial relieve y los melismas más prolongados recaen prácticamente sin excepción en las sílabas acentuadas. Observemos, por ejemplo, el dilatado melisma de "vincitur" en Dracho peringens, recurso bastante convincente para reflejar la alegría de los discípulos de Santiago al ver fracasados los malévolos planes de la matrona Luparia. De todas formas, la tónica general en cuanto al diseño melódico de las piezas es una compensada alternancia de pasajes silábicos con melismas de moderada extensión. Aunque las inflexiones melódicas en el repertorio gregoriano obedecen también en gran medida a la acentuación de las palabras, esta fijación no resulta tan rígida como la que advertimos en estos cantos.

La notación empleada en el fragmento es cuadrada con un grosor de unos 3 mm sobre una pauta. Es bien conocido que este sistema de escritura musical se centra ante todo en precisar las alturas melódicas en detrimento de otros aspectos de orden interpretativo. No obstante, observamos aún la presencia de neumas ornamentales como el quilisma o las licuescencias con un trazado en ambos casos que recuerda en buena medida a la variedad aquitana precedente. La pervivencia de estos símbolos especiales, en particular del quilisma, junto a la presumible tardía composición del oficio -más o menos en torno a mediados del siglo XIIIdeja entrever que aún en este periodo existía una preocupación hacia cuestiones de índole rítmica. La escasa presencia de quilismas en el Calixtino ${ }^{9}$, a su vez, representa otra prueba para reforzar la mayor vinculación de la música del fragmento con formas del pasado.

El examen de los textos revela una clara división en cuanto a contenido. Por un lado, las antífonas nos remiten al relato legendario de la traslación del cuerpo del apóstol hasta Galicia. Una narración sustentada en dos documentos que debían

9 Ibíd., 293. 
estar ya redactados en torno al año 900: la Epístola del Papa León y la Historia Translationis, a su vez un plagio de la de los Siete Varones Apostólicos ${ }^{10}$. Ambas leyendas se completan entre sí e incluso en algunos manuscritos se llegan a confundir ${ }^{11}$. Los textos de los responsorios, por el contrario, fueron compuestos expresamente con el fin de acomodarlos a la liturgia. A diferencia de las antífonas, su contenido carece de sentido narrativo, más bien cumple un objetivo claramente propagandístico: reforzar la imagen de Santiago como patrón de España y la de Compostela como lugar elegido por designio divino para albergar sus reliquias.

Ejemplo 1: Responsorio O magnum dei munus
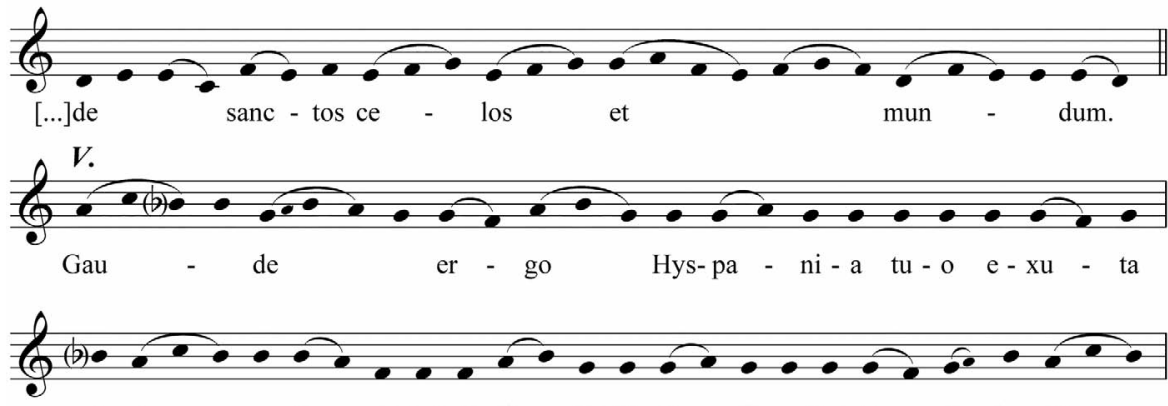

er-ro - re su-per-sti-cio - nis tri-pu - di-a tan-to il - lus-tra -

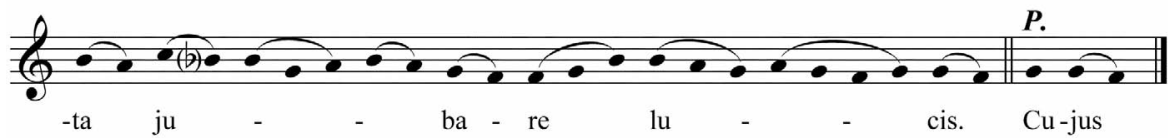

10 Conservamos cuatro o cinco redacciones de la Epístola del Papa León, la más antigua aparece copiada en un manuscrito de San Marcial de Limoges no muy avanzado el siglo X. Un poco más tarde se redacta en la abadía benedictina de San Pedro de Gembloux -en la actual Bélgica- la Historia Translationis; véase PÉREZ DE URBEL, Justo, Santiago y Compostela en la Historia (con amor y con verdad), Madrid 1977, 143 y 175.

11 Ibíd., 142. 
Ejemplo 2: Responsorio Sancta et preadmiranda
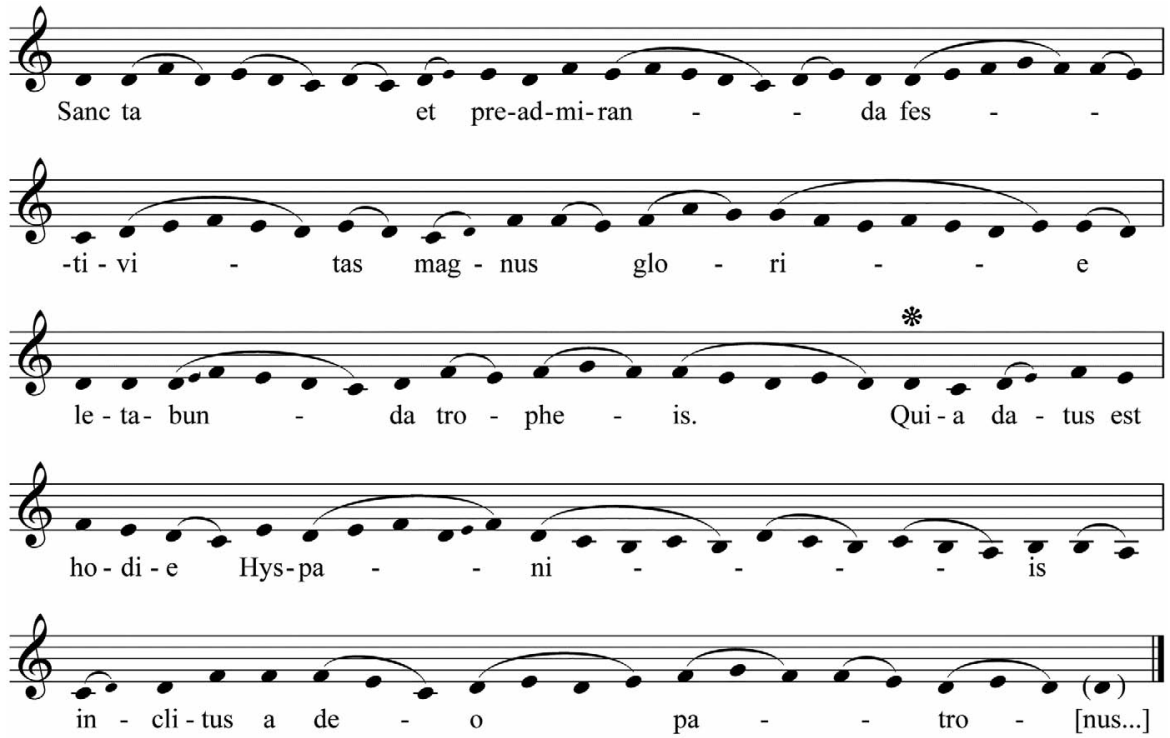

Ejemplo 3: Antífona Dracho peringens
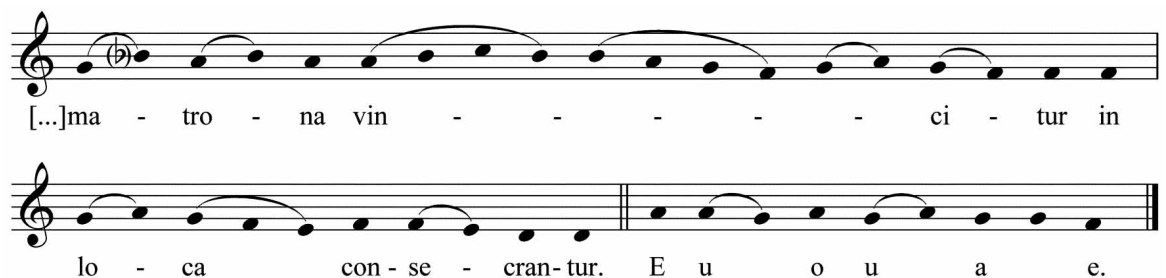

Ejemplo 4: Antífona Visis tantis
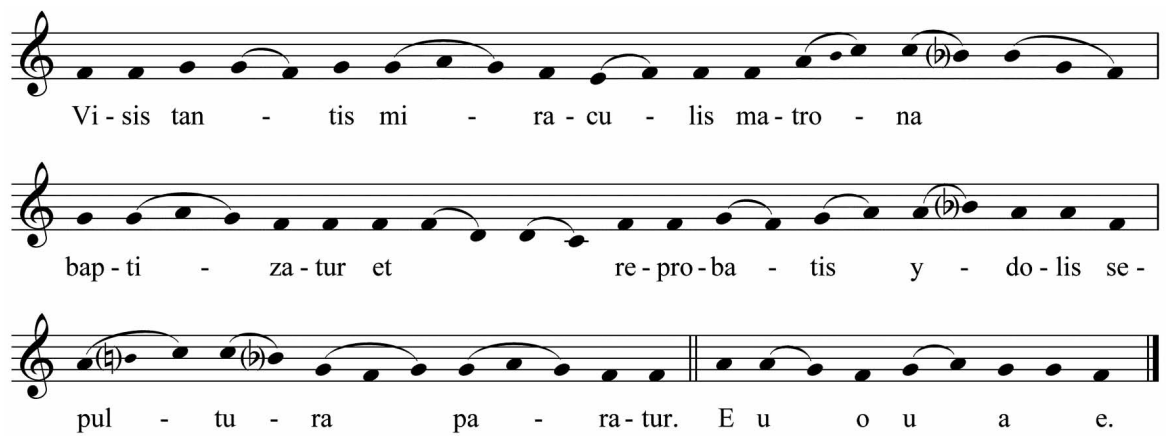
Ejemplo 5: Responsorio Felix valde

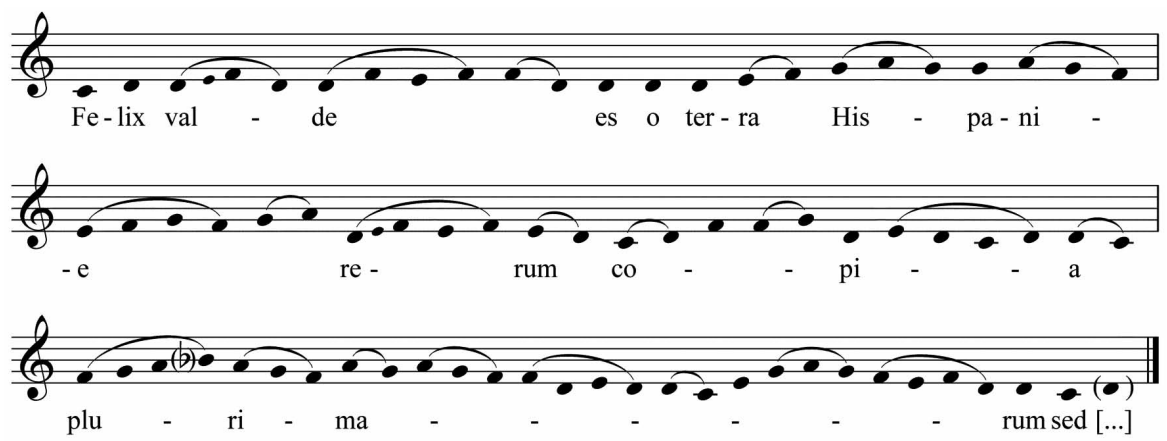

\section{GÉNESIS Y DIFUSIÓN DEL OFICIO}

El Oficio de la Traslación, tal como figura en el fragmento, no adquirió su forma definitiva seguramente hasta mediados del siglo XIII, y sólo tras un dilatado proceso de más de un siglo de duración. El origen de esta festividad se remonta a finales del siglo XI y surge en el marco de la sustitución de la liturgia nacional en favor de la romana. Dicho cambio implicaba la supresión de la fiesta del apóstol fijada el 30 de diciembre en el calendario hispano por la del 25 julio. Como la primera fecha gozaba de un notable arraigo en la Península Ibérica se buscó una solución que pasara por preservar ambas celebraciones. Amparándose en el modelo litúrgico empleado en San Martín de Tours, que ya por aquella época distinguía dos celebraciones (su muerte el 11 de noviembre, y su elección episcopal y traslación de su cuerpo el 4 de julio), se decidió crear dos fiestas de Santiago con contenido litúrgico diferenciado ${ }^{12}$. Dicha duplicación sería, a su vez, beneficiosa por dos motivos fundamentales: por un lado, al celebrar una fiesta en julio se fomentaría la venida de peregrinos ultrapirenáicos ayudados por unas condiciones climatológicas menos adversas ${ }^{13}$; y por otro, el hecho de mantener la fiesta de diciembre contentaría a un amplio sector del clero hispano deseoso de salvaguardar sus tradiciones.

Con vistas a superar las reticencias iniciales mostradas por Roma respecto a la autenticidad de las reliquias conservadas en Compostela, se decidió dotar a la fiesta del 30 de diciembre de un contenido neutro como era la conmemoración

12 David, Pierre, "Études sur le livre de St-Jacques attribué au pape Calixte II, I-V”, Bulletin des Etudes portugaises, 10 (1945), 12-13 y 19; 11 (1947), 130-31 y 154.

13 LópeZ Alsina, Fernando, "La posición de la Iglesia de Santiago en el siglo XII a través del Códice Calixtino", El Códice Calixtino y la música de su tiempo, 25. 
de la vocación apostólica de Santiago. Si bien, a lo largo del siglo XII, gracias a una posición más permisiva del Papado, fue introduciéndose la festividad de la Traslación ${ }^{14}$. Esta dualidad de conmemoraciones para la fiesta de diciembre se aprecia aún en el Codex Calixtinus. ¿Cuáles fueron las razones que impidieron la difusión y consiguiente popularización del repertorio del Codex? En relación al objeto de este estudio, debemos tener presente que el Calixtino, a pesar de ser prolijo en detalles, no distingue con repertorio propio la festividad de la Traslación. Por otra parte, en sus cantos se percibe un sustrato bíblico bastante acentuado, lo cual seguramente obedezca a la necesidad de ganarse el apoyo de Roma y a la inexistencia de una liturgia plenamente consolidada en Compostela tras el cambio de rito ${ }^{15}$. Además, el cursus de su oficio no queda del todo claro, ya que aglutina elementos seculares y monásticos ${ }^{16}$. En cierta medida, el Calixtino parece responder a un momento de reconversión de la liturgia monástica, aún activa

${ }^{14}$ Este proceso de afianzamiento tuvo que superar momentos críticos como la férrea oposición por parte del papa san Gregorio VII (1073-1085) a admitir la traslación del cuerpo del apóstol Santiago a España. Gracias al apoyo de la monarquía y la habilidad de los propios prelados compostelanos se consiguió que Pascual II en 1105 reconociera la autenticidad de las reliquias del apóstol custodiadas en Compostela; Ibíd., 25-29.

15 Pedro Romano Rocha afirma que el proceso de consolidación de la Consuetudo ecclesia Compostellance sería lento y coincidiría con el pontificado de Diego Gelmírez (1100-1139/40); RocHA, Pedro Romano, "La liturgia de Compostela a fines del siglo XII", O Portico da Gloria e o Arte do seu tempo. Actas del Simposio Internacional de Santiago de Compostela, 3-8 octubre 1988, A Coruña 1991, 399. Un proceso posiblemente ralentizado por la concepción cosmopolita de Compostela, foco en el cual convergerían diversas corrientes litúrgicas tanto nacionales como foráneas. De todas formas, sería conveniente efectuar estudios acerca de la penetración del rito romano en Galicia que posibiliten la profundización en estas cuestiones; DíAz y Díaz, Manuel C., Historia de las diócesis españolas 14. Iglesias de Santiago de Compostela y Tuy-Vigo, Madrid 2004, 35.

${ }^{16}$ Christopher Hohler aduce que el esquema del oficio es secular basándose en el número de salmos y antífonas para vísperas, la agrupación en grupos de tres de las antífonas y responsorios en maitines, la confusión en la numeración modal de los últimos responsorios de esta hora litúrgica y la inclusión de la antífona de "Nunc dimittis" en completas; HoHLER, Christopher, "A Note on Jacobus", Journal of the Warburg and Courtauld Institutes, 35 (1972), 43. Michel Huglo esgrime que es monástico por los 12 responsorios y 13 antífonas que se recogen para maitines; HugLo, Michel, "Les pièces notées du Codex Calixtinus", The Codex Calixtinus and the shrine of St. James, Tübingen 1992, 107. Susan Rankin ha aportado más recientemente otros dos argumentos para apoyar su concepción secular. En primer lugar, en el Argumentum Calixti pape de matutinis sancti Iacobis, inserto en el Codex entre las segundas vísperas y la misa de la vigilia, Calixto se refiere a los géneros litúrgicos en grupos de tres o sus múltiplos. Por otra parte, si se examina el contenido textual de las antífonas en maitines se advierte que su serie podría haber sido cortada perfectamente tras la novena. Los cantos restantes parecen más bien una capa añadida a una composición previa a la cual no daña; RANKIN, Susan, "Exultent gentes occidentales": The Compostelan Office of St James”, El Códice Calixtino y la música de su tiempo, 324-25. El mismo Codex parece no decantarse al respecto ya que contiene numerosas referencias tanto al clero secular (archiepiscopus, clerici...) como al regular (monachi, religiosi...); VIllanueva, Carlos, "Música y liturgia en Compostela a partir del Calixtino: El Oficio de Maitines y la Misa de la Vigilia del Apóstol", El Códice Calixtino y la música de su tiempo, 337. 
a finales del siglo XI en los focos de San Pelayo de Antealtares y de San Martín Pinario, por otra catedralicia, deseo ya patente desde el pontificado de Diego Peláez ${ }^{17}$. No extraña, en este sentido, que el mismo Codex evidencie escasas pruebas de uso $^{18}$.

En torno a comienzos del siglo XIII, ya con una liturgia local plenamente consolidada, la Ecclesia Compostellana debió constatar que la versión recogida en el Calixtino no cumplía todas las expectativas de cara a promocionar el culto del apóstol. A lo largo de la centuria precedente la ruta de peregrinación se había ido consolidando y su fama era creciente entre las diversas capas sociales ${ }^{19}$. Se hace por ello necesario recurrir a nuevas estrategias que evitasen que la fe del peregrino hacia Santiago se entibiara y fomentar, a la par, un sentimiento de unidad frente a la amenaza del Islam. Como respuesta a estas nuevas demandas se promocionó entre los fieles una imagen fantástica y heroica de Santiago, a todas luces beneficiosa en la lucha contra el sarraceno. Es en entonces cuando se popularizan relatos, cuanto más extraordinarios mejor, como el de la maravillosa aparición de Santiago en las batallas de Clavijo o Navas de Tolosa, el de su heroica lucha contra el mago Hermógenes recogida en la Passio Sancti Jacobi ${ }^{20}$, y cómo no, el de los avatares acontecidos en la venida prodigiosa de su cuerpo a la Península. Debemos tener en cuenta que este tipo de relatos fantásticos gozaron de una considerable credibilidad entre los fieles

\footnotetext{
17 Ibíd., 337-38.

18 Manuel C. Díaz y Díaz ha comprobado en su estudio codicológico del Calixtino la inexistencia de trazas de uso reiterado; DíAz y Díaz, Manuel C., El Códice Calixtino de la Catedral de Santiago, Santiago de Compostela, 1988. Según Elisardo Temperán sus cantos, salvo excepciones, no fueron interpretados; TEMPERÁn, Elisardo, El Libro I del Códice Calixtino de la catedral de Santiago de Compostela: ¿Un propio de la iglesia compostelana en el siglo XII?, Tesis Doctoral. Facultad de Liturgia, Roma 1991, 28 y 36. Otro factor que frenaría su propagación sería su misma concepción tan prolija en detalles, la cual difícilmente podría tener cabida en una liturgia que no fuera la compostelana; RANKIN, Susan, "'Exultent gentes occidentales‘”, 313. Tengamos además en cuenta que el Calixtino emplea una variedad de notación neumática francesa estrechamente vinculada a Nevers, un sistema de escritura, por otra parte, no difundido por la Península; HugLo, "Les pièces notées", 106. No obstante, hay autores, como José López-Calo, Paul Helmer o el mismo Michel Huglo, que afirman que su música llegó a tener cabida dentro del culto, basándose sobre todo en las rúbricas y en pequeños detalles de índole práctica; Helmer, Paul, The Mass of St. James. Solemn Mass for the Feast of the Passion of St. James of Compostela according to the Codex Calixtinus, Ottawa 1988; LóPeZ-CALO, José, La Música en la catedral de Santiago. vol. V. la Edad Media, La Coruña 1994; Huglo, "Les pièces notées", 110.

19 HerwaArden, Jan van, "Le pèlerinage a Saint-Jacques de Compostelle (XII ${ }^{\mathrm{e}}$ au XVIII ${ }^{\mathrm{e}}$ siècle)", Santiago de Compostela. 1000 ans de Pèlerinage Européen, Gand 1985, 71.

${ }^{20}$ La Passio Sancti Jacobi fue redactada alrededor del año 400, un periodo en el que florecieron numerosas narraciones salpicadas de elementos épicos y fantásticos de los héroes que habían hecho factible la victoria contra el paganismo y subsiguiente aceptación del Cristianismo en el Imperio Romano. Parece que este relato era ya conocido en la Península Ibérica antes del descubrimiento del sepulcro de Santiago en el siglo VIII. PÉrEZ DE Urbel, Santiago y Compostela, 77-80.
} 
durante el Medioevo ${ }^{21}$. Seguramente como fruto de estas inquietudes, sea en estos años cuando el Oficio de la Traslación se remodele en una versión definitiva.

Lamentablemente, apenas contamos con testimonios tempranos del oficio que posibiliten concretar mejor la fecha de su configuración. La misma Iglesia compostelana apenas conserva unos pocos fragmentos de índole litúrgica entre los siglos XII y XIV, a todas luces insuficientes en este sentido ${ }^{22}$. En el caso de Segovia, según se deduce de la datación del fragmento, parece que la fiesta de la Traslación estaba ya introducida a finales del siglo XIII. Sin embargo, su celebración no queda reflejada en el Breviario local B-288, fechado entre los siglos XIII y XV ${ }^{23}$. Únicamente su calendario menciona esta festividad, si bien su redacción resulta algo más tardía respecto al cuerpo principal del manuscrito ${ }^{24}$. Debemos esperar hasta el siglo XV para verificar su presencia en códices locales, como el citado Breviario B-272 o las Consuetudines ecclesice segobiensis del obispo Juan Arias Dávila (B-428), fechadas en $1484^{25}$. Toledo, parece que ignoró, al menos entre los siglos XII y XIII, la festividad de Santiago apóstol; de hecho, el Breviario local 33.5 ni siquiera recoge la celebración de la fiesta del 25 de julio ${ }^{26}$. Si bien, en este caso vislumbramos un componente religioso-político. A mediados del siglo XIII, la Iglesia de Toledo para defender su primacía frente a la pujante Compostela, sostuvo que la evangelización del apóstol en tierras españolas era un "cuento de monjas y viudas piadosas" 27 .

Los testimonios más tempranos que hemos localizado para el Oficio de la Traslación confirman, al igual que pasaba con el Calixtino, la inexistencia de un corpus musical diferenciado respecto al de la fiesta del 25 de julio. Nos referimos en concreto al fragmento de breviario neumado del siglo XII, localizado

\footnotetext{
21 Ibíd., 143.

${ }^{22}$ El primer documento íntegro de la liturgia compostelana para el Oficio no lo encontramos hasta el Breviario del Canónigo Miranda, fechado en la segunda mitad del siglo XV; JANINI, Manuscritos litúrgicos I, núm. 287, 243-44. Tampoco es mejor la situación en el caso de los impresos litúrgicos locales entre finales del siglo XV y primera mitad del XVI; OdRIOZOLA, Antonio, "Los libros litúrgicos impresos para la diócesis compostelana (siglo XV)", Cuadernos de Estudios Gallegos, 30 (1976-1977), 89-107.

23 JANINI, "Códices litúrgicos", núm. 9, 302-03; Ídem, Manuscritos litúrgicos I, núm. 309, pp. 26061.

${ }^{24}$ Segovia, AC: B-288, fol. $8 \mathrm{v}$.

${ }^{25}$ Segovia, AC: B-272, ff. 8r-10v; B-428, ff. 77v-78r. La consueta aparece descrita en ReYeS GómEZ, Fermín de los, "El obispo bibliófilo: Arias Dávila y los libros", Juan Parix: primer impresor en España, Segovia 2004, 243-44.

26 Toledo, BC: ms. 33.5, fol. 78r. Véase JaninI, José - GonZÁlvez, Ramón, Catálogo de los manuscritos litúrgicos de la catedral de Toledo, Toledo 1977, núm. 17, 64.

${ }^{27}$ García Villadd, Zacarías, Historia eclesiástica de España I, Madrid 1929, 30.
} 
en el Archivo de la Catedral de Orense ${ }^{28}$, y al Breviario neumado proveniente del monasterio de Santa Cruz de Coímbra (Oporto, BM: ms. 1151) fechado a finales del siglo XIII ${ }^{29}$. Tanto los cantos como su orden en el fragmento de Orense resultan bastante semejantes a redacciones más tardías verificadas en Segovia, Toledo o Uclés para la fiesta del 25 de julio ${ }^{30}$. Las únicas divergencias que hemos encontrado es que las fuentes segovianas y el 33.7 de Toledo indican como sexto responsorio $O$ venerande Christi apostole propagator en vez de Sancte Jacobe Christi apostole, y que Instante vero tempore -no In tantem veratem como transcribe Rey Olleros- figura como octavo responsorio y no en séptimo lugar como el manuscrito de Orense. Uclés incorpora el mencionado responsorio Sancte Jacobe Christi apostole en sexta posición como Orense pero no incluye Instante vero tempore en su serie responsorial. En el caso del códice de Coímbra (ff. 100r-103r) sólo se recoge una pequeña selección de cantos propios: el responsorio Sancte Jacobe Christi apostole para las primeras vísperas, la antífona de "magnificat" Sancte apostole domini preciose, el invitatorio Venite omnes Christicole, el responsorio noveno de maitines $O$ speciale decus generali y la antífona de "benedictus" O beate Jacobe omnium corde. Todas estas piezas, a excepción de Sancte apostole domini preciose, las hemos verificado de nuevo en Segovia, Toledo y Uclés siempre para la fiesta estival: $O$ beate Jacobe omnium corde como antífona de "magnificat" en las segundas vísperas de Segovia, Sancte Jacobe Christi apostole como sexto responsorio de maitines en Uclés y $O$ speciale decus como responsorio de cierre en Segovia, Toledo y Uclés.

Para conocer mejor el alcance real de la festividad de la Traslación hemos recurrido al ms. 13059 de la Biblioteca Nacional de Madrid, procedente de la colección Burriel, en donde se transcriben distintos calendarios litúrgicos de breviarios peninsulares fechados entre los siglos $\mathrm{XV}$ y $\mathrm{XVI}^{31}$. De igual modo,

\footnotetext{
28 Véase fragmento 3 en Rey Olleros, Manuel, La Música Medieval en Ourense. I. Pergaminos musicales del archivo catedralicio, Ourense 2002, 35-38.

29 Véase Nascimento, Aires Augusto - Meirinhos, José Francisco, Catálogo dos Códices da Livraria de Mão do Mosteiro de Santa Cruz de Coimbra na Biblioteca Pública Municipal do Porto, Porto 1997, 377-78. Resulta bastante probable que la festividad de la Traslación del apóstol Santiago fuera introducida en el Monasterio de Santa Cruz de Coímbra en torno a mediados del siglo XII a tenor de la datación del calendario de uno de sus códices: el Salterio, Breviario y Misal fechado entre mediados del siglo XII y finales del XIII (Oporto, BM: ms. 843, fol. 187r); Ibíd., 282-85.

${ }^{30}$ El Oficio de Santiago apóstol del 25 de julio figura en Segovia, AC: B-272, ff. 95v-97v del Santoral y B-428, ff. 95v-96r; Toledo, BC: ms. 33.7, ff. 356v-359r; Uclés (Madrid, BN: ms. 240, ff. 399r-404v).

31 Véase Janini, José - SerRano, José, Manuscritos litúrgicos de la Biblioteca Nacional, Madrid 1969, núm. 139, 172. Este manuscrito incluye los calendarios de las diócesis de Ávila, Braga, Burgos, Coria, Lérida, Palencia, Santiago de Compostela, Segovia, Sevilla, Sigüenza, Tortosa y Valencia.
} 
hemos ampliado el espectro incorporando las fuentes citadas por Analecta Hymnica $^{32}$ más otras recabadas tras consulta personal ${ }^{33}$.

\section{-Diócesis que incluyen la festividad:}

- Ávila, Braga, Burgo de Osma, Burgos, Córdoba, Coria, Palencia, Santiago de Compostela, Segovia, Sevilla y Sigüenza

\section{-Diócesis que no incluyen la festividad:}

- Barcelona, Lérida, Tarazona, Tortosa, Valencia y Vic

Según se desprende de este cuadro, la festividad de la Traslación tuvo amplia difusión en Castilla y Portugal, mientras que las diócesis de la Corona de Aragón se mantuvieron al margen. Esta acogida en tierras portuguesas se debe a la vinculación de buena parte de sus diócesis a la metrópoli compostelana durante la Edad $\mathrm{Media}^{34}$, a su proximidad geográfica al santuario, y a la amplia difusión de la devoción a Santiago en sus tierras ${ }^{35}$. En el caso de Castilla, la extensión de su

32 Dreves, Analecta Hymnica Medii Aevi XVII, 120. Las fuentes que cita son el Breviario del canónigo Miranda, el Breviario de Uclés de la Biblioteca Nacional de Madrid, el Breviario de Compostela impreso en 1497, el Breviario de Córdoba impreso en 1524 y el Breviario de Compostela impreso en Salamanca en 1569. Acerca de los impresos consúltese ODRIOzOLA, Antonio, Catálogo de libros litúrgicos españoles y portugueses, impresos en los siglos XV y XVI, Pontevedra 1996, núm. 254, 236-37 (Breviario de Compostela de 1497); núm. 206, 206-07 (Breviario de Córdoba de 1524); núm. 256, 236-39 (Breviario de Compostela de 1569).

33 En concreto, hemos consultado los calendarios o el mismo oficio de la Traslación, si tal es recogido, en los siguientes manuscritos: Burgos, AC: ms. 19, Breviario monástico del siglo XII; Tarazona, AC: ms. 92, Misal del siglo XIV; Vic, AC: ms. 81, Breviario vicense de la primera mitad del siglo XIV; Vic, AC: ms. 83, Breviario de Barcelona de la segunda mitad del siglo XIV; Burgo de Osma, BC: ms. 2, Breviario de la segunda mitad del siglo XV; Toledo, BC: mss. 33.7 y 33.9, Breviarios del siglo XV. Todas las fuentes, a excepción de las toledanas, están catalogadas en JANINI, Manuscritos litúrgicos I, núm. 3, 37-38 (Osma); núm. 21, 51 (Burgos); II, núm. 654, 206-07 (Tarazona); núm. 835, 321 (Vic); núm. 837, 322 (Barcelona). Para los códices de Toledo véase JANINI - GonZÁLVEZ, núm. 19 y 21, 6567. Aunque el ms. 19 de la Capitular de Burgos no sea diocesano, Janini apunta que su calendario se copió en el siglo XIV en el monasterio de San Pedro de Cardeña, sito en su provincia; resulta bastante factible, a tenor de este dato, que su Iglesia diocesana recogiese también la celebración de la Traslación del apóstol. Recordar, igualmente, la inclusión de esta festividad en Oporto, BM: ms. 1151, Breviario neumado de finales del siglo XIII, y Oporto, BM: ms. 843, Salterio, Breviario y Misal datado entre mediados del siglo XII y finales del XIII, códices provenientes del Monasterio de Santa Cruz de Coímbra. 34 Tras reiteradas peticiones, en 1120 Calixto II decidió restituir en Compostela la antigua metrópoli hispano-visigoda de Mérida, la cual comprendía numerosas diócesis portuguesas. Esta situación perduró hasta los años 1393-1394, en los cuales se realiza un nuevo reparto por el cual Compostela cedió la administración de las sufragáneas portuguesas en favor de Braga y Lisboa, adquiriendo en compensación las sedes episcopales gallegas anteriormente dependientes de Braga; MANSILLA, Demetrio, "Geografía eclesiástica", Diccionario de Historia Eclesiástica de España II, Madrid 1972, 991-93. Todavía en la segunda mitad del siglo XV y primera mitad del XVI eran usados en la diócesis de Lisboa algunos libros compostelanos; RocHA, "La liturgia de Compostela", 406.

35 Una buena prueba de ello es la celebración de sus dos fiestas en numerosas diócesis portuguesas hasta los siglos XVII y XVIII; Ibíd., 407. 
culto presenta unas claras connotaciones políticas: la imagen de Santiago como referente espiritual hispano y baluarte frente al Islam resultaba sumamente beneficiosa tanto a la monarquía como a las distintas Iglesias locales. El riesgo de supeditación a los intereses castellanos debió, por contra, impedir la propagación del culto al apóstol en territorios de la Corona de Aragón. Además, debemos valorar otros dos aspectos: por un lado, el hecho mismo de la predicación en España fue visto con recelo en el ámbito catalán desde antiguo ${ }^{36}$; por otro, la fiesta del 25 de julio entraba en conflicto con la de San Cugat, una devoción de notable raigambre local ${ }^{37}$.

Otro punto de interés es constatar el grado de uniformidad que evidencian las fuentes que incorporan este oficio. La propia ordenación de las antífonas y sobre todo de los responsorios ${ }^{38}$ puede indicar mucho acerca de la vinculación de un códice respecto a una tradición litúrgica. La tardía compilación del oficio, datada como hemos visto a mediados del siglo XIII, podría hacer pensar en una difusión bastante homogénea, ya que para esta época la mayoría de las consuetas peninsulares estaban fijadas. No obstante, hemos encontrado pequeñas diferencias tanto en el orden de las piezas como en su contenido textual, especialmente en Segovia. En el cuadro siguiente recogemos las distintas variantes halladas en los íncipits de los cantos en Segovia, Toledo, Uclés y Osma. La redacción que tomamos como referencia es la de Segovia, al ser la sede episcopal a la que pertenece el fragmento analizado, sin que ello implique algún tipo de autoridad sobre las demás. En negrita aparecen las variantes significativas, es decir aquellas que afectan al ordenamiento de las piezas respecto a Segovia, y en cursiva las que sólo atañen a distintas redacciones de un mismo canto. Cuando no hay cambios empleamos (=) y para las partes de texto no incluidas en los códices por pérdida de folios usamos (x).

\footnotetext{
${ }^{36}$ En el siglo X el abad de Santa Cecilia de Montserrat viaja a Compostela con el fin de ser consagrado arzobispo de Tarragona, sede aún ocupada por los agarenos. Aunque una vez allí consigue que el rey Sancho de León y los obispos gallegos accedan a su petición, a su regreso a tierras catalanas los obispos de Barcelona, Gerona, Urgel y Narbona se oponen a tal nombramiento escudándose en el argumento de que Santiago no vino a España. Aún así, se admitía la autenticidad de las reliquias, cosa que no sucede, por ejemplo, en Toledo en época coetánea; PÉREZ DE URBEL, Santiago y Compostela, 203-05.

37 Se puede observar en fuentes catalanas como San Cugat ocupa buena parte del culto del 25 de julio; Vic, AC: ms. 81, ff. CCCXLVI (321v) - CCCXLCIII (323r); y ms. 83, ff. 386r (CXIIIIr) $387 \mathrm{v}(\mathrm{CXVv})$.

38 Victor Leroquais aduce, en este sentido, que las series de responsorios deben ser consideradas como sello distintivo de cada Iglesia ya que, por un lado, permanecen constantes dentro de la liturgia de cada diócesis, y por otro, varían de una Iglesia a otra. Véase LeRoQuAIs, Victor, Les bréviaires manuscrits des bibliothèques publiques de France I, Paris 1934, LXIII y LXXVIII-LXXXI.
} 
SERIE RESPONSORIAL DE MAITINES

\begin{tabular}{|c|c|c|c|}
\hline $\begin{array}{c}\text { Segovia } \\
\mathrm{AC}, \mathrm{mss} . \mathrm{B}-272 \text { / B-428 }\end{array}$ & $\begin{array}{c}\text { Osma } \\
\text { BC, ms. } 2\end{array}$ & $\begin{array}{c}\text { Uclés } \\
\text { BN, ms. } 240\end{array}$ & $\begin{array}{c}\text { Toledo } \\
\text { BC, ms. } 33.7\end{array}$ \\
\hline $\begin{array}{l}\text { R.1 Adest nobis valde letabunda } \\
\text { V. Divini numeris }\end{array}$ & $=$ & $=$ & $=$ \\
\hline $\begin{array}{l}\text { R.2 Post passionem suam } \\
\text { V. Applicantes Irie gaudio }\end{array}$ & $\begin{array}{c}\text { V. Applicantes Irie } \\
\text { pie gaudio }\end{array}$ & $=$ & $=$ \\
\hline $\begin{array}{l}\text { R.3 Sublevantes autem discipuli } \\
\text { V. Ibi vero pre timore }\end{array}$ & $=$ & $=$ & $=$ \\
\hline $\begin{array}{l}\text { R.4 Humato corpore } \\
\text { V. Construentes sepulcrum }\end{array}$ & $=$ & $=$ & $=$ \\
\hline $\begin{array}{l}\text { R.5 O magnum dei munus } \\
\text { V. Gaude ergo Hyspania }\end{array}$ & $=$ & $\begin{array}{l}\text { R.O magnum } \\
\text { dei domus }\end{array}$ & $=$ \\
\hline $\begin{array}{l}\text { R.6 Sancta et preadmiranda } \\
\text { V. Urbibus tu feliciorum }\end{array}$ & $\begin{array}{l}\text { V. Urbibus tu } \\
\text { felicior }\end{array}$ & $=$ & $=$ \\
\hline $\begin{array}{l}\text { R.7 Felix valde es o terra } \\
\text { V. Olim tu quidem }\end{array}$ & $\mathrm{x}$ & $=$ & $=$ \\
\hline $\begin{array}{l}\text { R.8 Alme perpetui luminis lux } \\
\text { V. Sedulus esto benigne }\end{array}$ & $\mathrm{x}$ & $\begin{array}{l}\text { R. O venerande } \\
\text { V. Ut nos tibi }\end{array}$ & $\begin{array}{l}\text { R. O venerande } \\
\text { V. Ut nos tibi }\end{array}$ \\
\hline $\begin{array}{l}\text { R.9 O beata dies populo } \\
\text { V. O quam letabunda }\end{array}$ & $\mathrm{x}$ & $=$ & $=$ \\
\hline
\end{tabular}

SERIE ANTIFONAL DE MAITINES

\begin{tabular}{|l|c|c|c|}
\hline \multicolumn{1}{|c|}{$\begin{array}{c}\text { Segovia } \\
\text { AC, mss. B-272 / B-428 }\end{array}$} & $\begin{array}{c}\text { Osma } \\
\text { BC, } \mathrm{ms.} \text { 2 }\end{array}$ & $\begin{array}{c}\text { Uclés } \\
\text { BN, ms. 240 }\end{array}$ & $\begin{array}{c}\text { Toledo } \\
\text { BC, ms. 33.7 }\end{array}$ \\
\hline $\begin{array}{c}\text { A.1 Multis fulgens miraculis } \\
\text { (Miraculis dies hec } \text { en B-272) }\end{array}$ & $=$ & $=$ & $=$ \\
\hline A.2 In tenebris sedentibus & $=$ & $=$ & $=$ \\
\hline A.3 Isto gaudens Hyspania & $=$ & $=$ & $=$ \\
\hline A.4 Per maris undas ducitur & $=$ & $=$ & A. Per maris et undas \\
\hline A.5 Quam intrantes discipuli & $=$ & $=$ & $=$ \\
\hline A.6 Post dies septem Irie & $=$ & $=$ & $=$ \\
\hline A.7 A rege locus petitur & $=$ & $=$ & A. Dracho ingens \\
\hline A.8 Dracho peringens rumpitur & A. Dracho ingens & $=$ & $=$ \\
\hline A.9 Visis tantis miraculis & $=$ & $=$ & \\
\hline
\end{tabular}


EL OFICIO DE LA TRASLACIÓN DEL APÓSTOL SANTIAGO EN LA BAJA EDAD MEDIA: ...

SERIE ANTIFONAL PARA LAUDES Y SEGUNDAS VÍSPERAS ${ }^{39}$

\begin{tabular}{|l|c|c|}
\hline \multicolumn{1}{|c|}{$\begin{array}{c}\text { Segovia } \\
\text { AC, mss. B-272 / B-428 }\end{array}$} & $\begin{array}{c}\text { Uclés } \\
\text { BN, ms. } 240\end{array}$ & $\begin{array}{c}\text { Toledo } \\
\text { BC, } \mathrm{ms} .33 .7\end{array}$ \\
\hline $\begin{array}{l}\text { A.1 Adest dies } \\
\text { (Beatus in quo Jacobus en B-272) } \\
\text { A.2 Exultet hoc Hyspania duce }\end{array}$ & $=$ & $=$ \\
\hline A.3 Sacra gaude Compostella & A. Felix o tu Gallecia & A. Felix o tu Gallecia \\
\hline A.4 Omnis populi benedicite & A. Sacra gaude & A. Sacra gaude \\
\hline A.5 O decus Gallecie & $=$ & $=$ \\
\hline A. Ben. Gaudeat plebs gallecianorum & $=$ & $=$ \\
\hline A. Magn. O lux et decus & $=$ & $=$ \\
\hline
\end{tabular}

El responsorio Alme perpetui, verificado sólo en Segovia, y las antífonas $O$ lux et decus y Gaudeat plebs gallecianorum constituyen los únicos textos que aparecen en el Calixtino. No obstante, en el Codex la redacción de Alme perpetui consta como antífona de "Nunc dimittis" en completas ${ }^{40}$, mientras que en las fuentes segovianas figura como cuerpo de un responsorio. Esta segunda versión resulta algo más abreviada respecto a la de la antífona:

\section{Codex Calixtino:}

- Alma perpetui luminis lux apostole Jacobe obscena tuorum intima famulorum illumina ut valeant tempora sic ducere secli quo valeant gaudia captare vite ${ }^{41}$

\section{Breviario de Segovia B-272:}

- Alme perpetui luminis lux apostole Jacobe obcena tuorum intima famulorum illumina ut valeant gaudia captare vite

Susan Rankin afirma que es posible que tanto el texto como la música de $O$ lux et decus tuvieran un origen desde Gaudeat plebs, ya que emplean un lenguaje melódico bastante parecido; de hecho, el resto de antífonas de modo III en el Calixtino remiten a otro modelo ${ }^{42}$. En vista de estas apreciaciones, podría ser factible

\footnotetext{
${ }^{40}$ La melodía de esta antífona en el Calixtino se apropia de la del Ave regina calorum; incluso, llega a imitar algunas de sus características estructurales y fonéticas. En base a esto, Susan Rankin llega a afirmar que cuando se cantara Alme perpetui se establecería una especie de nexo entre María y el apóstol Santiago fundamentado en la frecuente interpretación de la antífona mariana; RANKIN, "Exultent gentes occidentales", 328.

${ }^{41}$ Texto tomado de la trascripción de WAGNER, Peter, Die Gesänge der Jakobusliturgie zu Santiago de Compostela aus dem sog. Codex Calixtinus, Freiburg 1931, 63.

42 RANKIN, "Exultent gentes occidentales", 320.
} 
pensar en una génesis diferenciada de estas tres piezas respecto al resto de cantos del Codex, lo cual les posibilitó una mayor difusión.

Llaman igualmente la atención las divergencias en la elección y ordenamiento de los cantos entre Segovia y el resto de fuentes consultadas. Aunque no sean muy importantes, podrían manifestar un deseo de individualizar la costumbre local aún en época tardía o, al menos, que la tradición que recibe Segovia proviene de otros cauces. A pesar de su aparente discordancia, las antífonas Multis fulgens miraculi / Miraculis dies hec y Adest dies / Beatus in quo Jacobus son en realidad variaciones de un mismo texto. Sorprende que las mismas fuentes segovianas discrepen en la redacción de estos cantos, lo cual prueba que la tradición dentro de una misma Iglesia distaba de estar totalmente unificada.

COMPARACIÓN DE LOS TEXTOS: Multis fulgens miraculi / Miraculis dies hec y Adest dies / Beatus in quo Jacobus

- Multis fulgens miraculis dies hec hodierna datur jocunda populis leticia superna

- Miraculis dies hec hodierna datur jocunda populis leticia superna

- Adest dies in quo Jacobus terree datur Hyspanie dux et patronus inclitus

- Beatus in quo Jacobus terree datur Hyspanie dux et patronus inclitus

Señalar también que los responsorios $O$ venerande y Alme perpetui y la antífona $O$ lux et decus figuran en la fiesta del 25 de julio en algunas de las fuentes examinadas. Ciertamente, el carácter ambivalente de sus textos los hace hábiles para ser interpretados en ambas festividades.

La versión del Oficio de la Traslación, tal como es recogida en el fragmento segoviano, debió estar vigente hasta la uniformización de los usos litúrgicos dictaminada en Trento. El hecho de que presentasen unos textos sin fundamento bíblico y de naturaleza poética, caso de las antífonas, fueron motivos suficientes para forzar su exclusión ${ }^{43}$. No obstante, antes de la reunión conciliar hallamos pruebas en Segovia que atestiguan la remodelación del oficio: la edición impresa del Breviario local de 1527 excluye la totalidad de cantos propios, a excepción del himno Adest dies letitie, y prescribe en su lugar los

\footnotetext{
43 Tras Trento fueron erradicados, salvo muy pocas excepciones, los oficios en verso; WAGENER, Heinz, "Die liturgischen Gesänge im 15. und 16. Jahrhundert", Geschichte der katholischen Kirchenmusik 1, Kassel 1972, 452. Desde Roma incluso se empezó a poner en duda por esta época la autenticidad de la predicación del apóstol Santiago en España. Aunque en la edición del Martirologio Romano de 1586 se había admitido su venida, esta hipótesis fue cuestionada por la Comisión formada en 1592 para revisar el Breviario. Tras un largo forcejeo, finalmente se consiguió que la redacción del Breviario de Urbano VIII en 1631 admitiese este hecho; García VILLADA, Historia eclesiástica de España, 30-40.
} 
de Navidad ${ }^{44}$. Seguramente debió influir en esta modificación la ubicación de la fiesta dentro de la octava de Navidad y su menor rango litúrgico respecto a la del 25 de julio ${ }^{45}$. Otro dato de interés es que tras el hallazgo de las reliquias de San Frutos en 1471 se habilitase en la antigua catedral segoviana una capilla a su culto anteriormente destinada a Santiago ${ }^{46}$. Ello induce a pensar que hubo una disminución o al menos un estancamiento de la devoción al apóstol por estas tierras en el tramo final del siglo XV. Además, debemos tener presente que uno de los cimientos sobre los que se había consolidado su culto -la creencia en su acción benéfica frente al peligro del Islam- se había desvanecido con la culminación de la Reconquista.

Al terminar esta indagación acerca del Oficio de la Traslación del apóstol Santiago, no me resta más que animar a la realización de investigaciones sobre el canto litúrgico a partir de la Baja Edad Media, un periodo bastante descuidado por la musicología en general. Una reconstrucción musical de este oficio y de otros muchos que se desarrollaron en algún momento de la historia y cayeron posteriormente en el olvido puede ser, sin duda, muy beneficiosa para conocer los criterios que rigieron la composición y difusión de la monodia litúrgica a través del tiempo.

\footnotetext{
${ }^{44}$ Segovia, AC: E-37, ff. 246r-247r. Acerca del breviario véase n ${ }^{\circ} 11$ de la relación de libros raros en VAlverde del Barrio, Cristino, Catálogo de Incunables y Libros Raros de la Santa Iglesia Catedral de Segovia, Segovia 1930, 197-98. Consúltese también Odriozola, Catálogo de libros litúrgicos, núm. 260, 239 y 241.

45 La consulta de un calendario segoviano datado en torno a 1400, una fecha por tanto en la que la fiesta estaba plenamente implantada, permite advertir que la celebración estival era con todas las capas, mientras que la de la Traslación era una categoría inferior -cuatro capas-; si bien, este último grado es compartido con advocaciones de notable arraigo como Santa Cecilia, San Clemente, el apóstol Andrés, o San Frutos, patrón de la diócesis; véase Segovia, AC: C-421/3, Libro de Pitanzas, $\sin$ foliar.

${ }^{46}$ LóPez Díez, María, Los Trastámara en Segovia. Juan Guas, maestro de obras reales, Segovia 2006, 22 y 64. Acerca del hallazgo de las reliquias consúltese también CONTRERAS JiMÉNEZ, María Eugenia, "Noticias sobre la antigua catedral de Segovia. El hallazgo de San Frutos", Anuario de Estudios Medievales, 19 (1989) 507-31, en particular la p. 515.
} 
Oficio de la Traslación del apóstol Santiago (Segovia, AC: Museo 24)

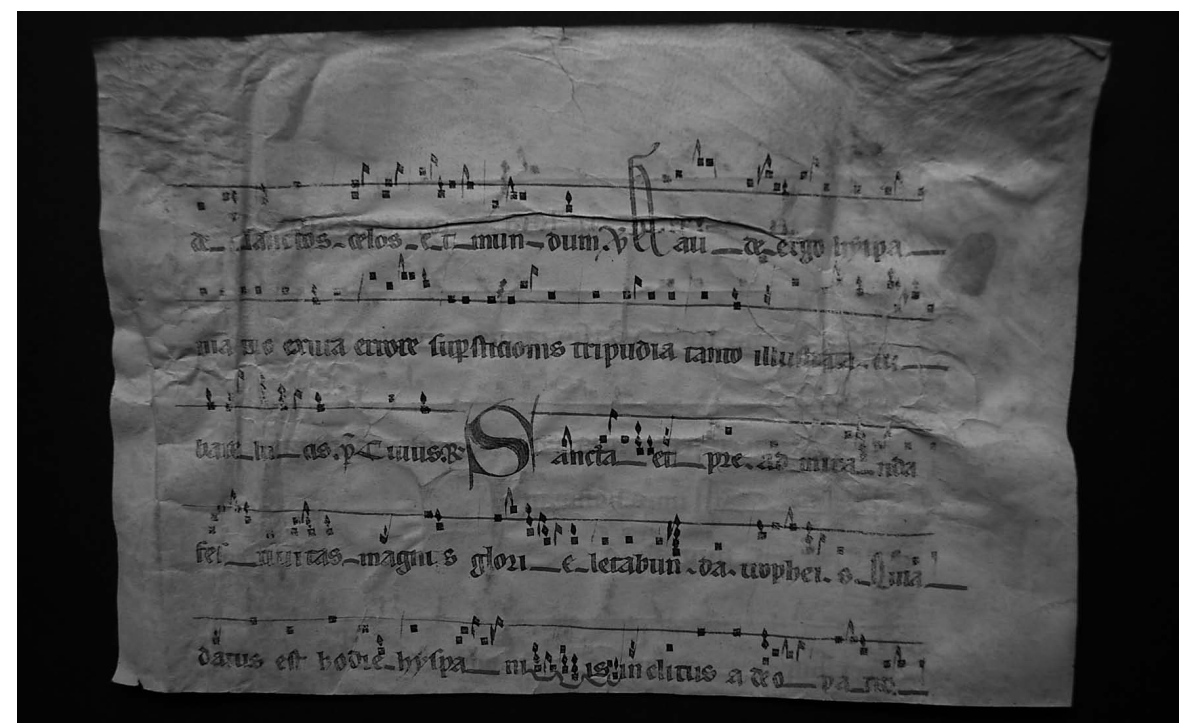

Folio recto

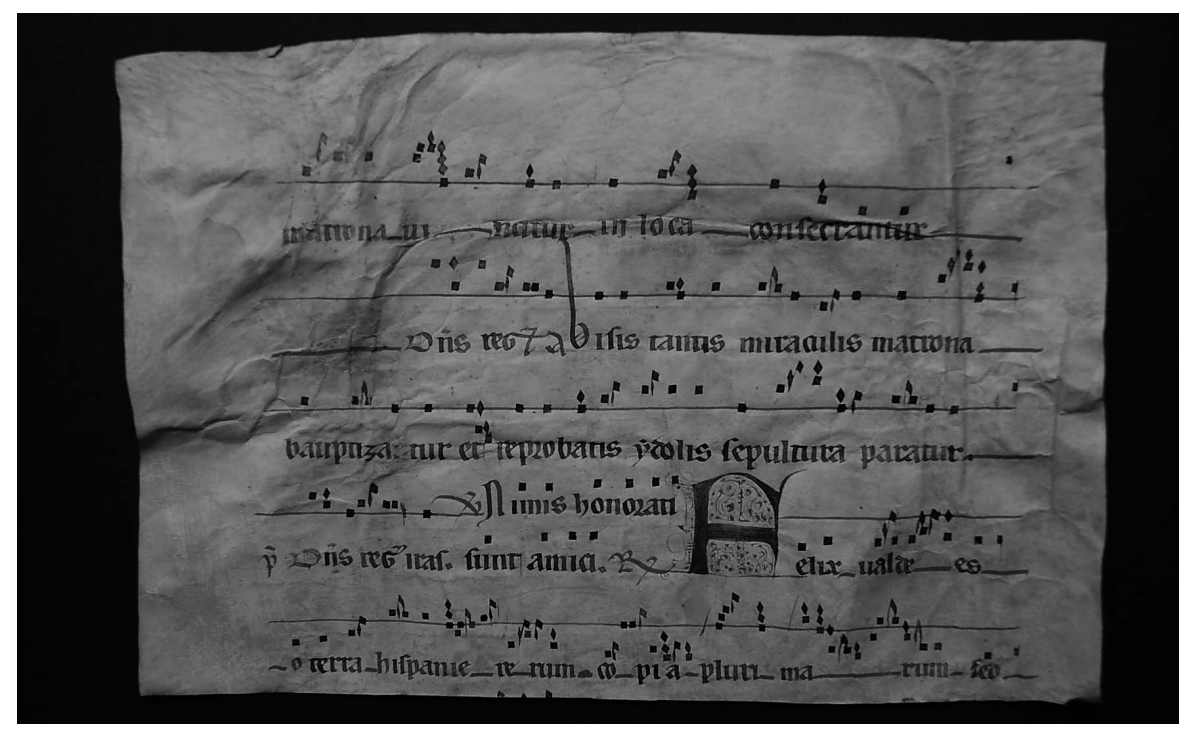

Folio verso 